\title{
Exogenous Controls Increase Negative Call Veracity in Multiplexed, Quantitative PCR Assays for Phakopsora pachyrhizi
}

James S. Haudenshield, United States Department of Agriculture-Agricultural Research Service (USDA-ARS); and Glen L. Hartman, USDA-ARS and Department of Crop Sciences, University of Illinois, Urbana 61801 \begin{abstract}
Phakopsora pachyrhizi. Plant Dis. 95:343-352.
Quantitative polymerase chain reaction (Q-PCR) utilizing specific primer sequences and a fluorogenic, $5^{\prime}$-exonuclease linear hydrolysis probe is well established as a detection and identification method for Phakopsora pachyrhizi and P. meibomiae, two rust pathogens of soybean. Because of the extreme sensitivity of Q-PCR, the DNA of single urediniospores of these fungi can be detected from total DNA extracts of environmental samples. However, some DNA preparations unpredictably contain PCR inhibitors that increase the frequency of false negatives indistinguishable from true negatives. Three synthetic DNA molecules of arbitrary sequence were constructed as multiplexed internal controls (ICs) to cull false-negative results by producing a positive signal to validate the PCR process within each individual reaction. The first two, PpaIC and PmeIC, are a single-stranded oligonucleotide
\end{abstract}

Abstract

Haudenshield, J. S., and Hartman, G. L. 2011. Exogenous controls increase negative call veracity in multiplexed, quantitative PCR assays for

flanked by sequences complementary to the primers of either the $P$. pachyrhizi or $P$. meibomiae primary assay but hybridizing to a unique fluorogenic probe; the third contains unique primer- and probe-binding sequences, and was prepared as a cloned DNA fragment in a linearized plasmid. These ICs neither qualitatively nor quantitatively affected their primary assays. PpaIC and PmeIC were shown to successfully identify false-negative reactions resulting from endogenous or exogenous inhibitors, and can be readily adapted to function in a variety of diagnostic Q-PCR assays; the plasmid was found to successfully validate true negatives in similar Q-PCR assays for other soybean pathogens, as well as to function as a tracer molecule during DNA extraction and recovery.
Negative results frequently do not generate the sensational impact of positives and, as such, may not as often elicit the "prove it" response. In diagnostic quantitative polymerase chain reaction (QPCR) assays, false negatives can be produced by multiple factors: operator error during reaction assembly, physical component failure (leaking reaction tube, wear and damage to fiber optics and moving parts, and so on), spoiled reagents, off-target priming of a competing nonfluorogenic amplicon, or inhibitors to the PCR chemistry carried through (or introduced by) the DNA isolation process (chelating agents, detergents, proteases, phenolics, particulates, immobilants, and so on; $2,12,14,18,19)$. With environmental samples or inconsistent tissue specimen types, the presence of inhibitors can be particularly vexing, because they may occur sporadically and unpredictably, despite identical sample handling and processing procedures, and may be nonuniformly distributed among assay replicates. Field diagnostics, as well as our ongoing research projects on Phakopsora pachyrhizi, require extraction of the potential pathogen DNA from spores or mycelium in soil or fresh, decaying, or dried plant tissues, and from various artificial substrates such as cellophane tape and carbohydrate capture media. Crop security, conscientious disease management, commercial liability, and sound scientific research all demand confidence in the

Corresponding author: G. Hartman, E-mail: ghartman@illinois.edu

* The $e$-Xtra logo stands for "electronic extra" and indicates that Figures 4 and 5 appear in color in the online edition.

Accepted for publication 28 October 2010.

doi:10.1094/PDIS-01-10-0023

This article is in the public domain and not copyrightable. It may be freely reprinted with customary crediting of the source. The American Phytopathological Society, 2011. validity of a negative result. Unfortunately, many researchers and diagnostic laboratories, including those working with soybean rust, do not have available specific internal controls (ICs) to reveal false negatives when they occur.

A variety of approaches have been devised to identify false negatives, because they are a common and problematic quality issue in PCR-based diagnostics. One approach is to amplify, either in parallel or in multiplex, an endogenous target sequence expected to be ubiquitously present, independent of primary target occurrence, such as a housekeeping gene in assays for mutations elsewhere in the genome (20) or for the presence of engineered transgenes $(4,11)$, or a host gene in assays for a pathogen in samples of host tissue (13). Such endogenous-target approaches have the added benefit of affirming the integrity of the DNA (or RNA) extracted from the specimen. However, they suffer the liability of possible interference with the primary assay if the endogenous target is present in excess over the anticipated quantity of primary target, unless amplification of the excess target is limited by reducing the supply of corresponding primers. They are also impractical when screening environmental samples where an endogenous target may not be present in uniform quantities, if at all. Another approach is to include (as a spiked, exogenous reagent) a secondary, co-amplified target, as in gelbased, ${ }^{32} \mathrm{P}$-labeled quantifications $(1,2,10)$ or real-time quantifications (21). This approach offers a controlled, unique IC target, positively present in the assay, whose amplification will attest to the validity of the assay itself. Such ICs may be derivative of $(8,24)$ or unrelated to the sequence of the primary target (17) or be completely artificial (21) and, for some applications, are available commercially (e.g., Exogenous Internal Positive Control Kit; Applied Biosystems, Foster City, CA). Unfortunately, there appears to be reluctance in the literature to reveal the sequences of these exogenous Q-PCR IC targets, making difficult the adoption of otherwise inexpensive ICs, an obstacle 
further compounded by the expense and limited fluorochrome types of the commercial products.

Some researchers, when faced with PCR inhibitors, have had success by dilution of the DNA sample, modifications to the extraction protocol (16), or addition of suppressors of inhibition, such as bovine albumin (12). Although the dilution method is straightforward and often effective, it does not address a number of the potential causes of false negatives (e.g., operator error or component failure). Furthermore, dilution has the consequence of reducing the target DNA concentration and may be impractical if the target is expected to be rare, such as with certain environmental or clinical samples. If the target is diluted beyond the validated range of the assay in order to eliminate inhibition, all that has been achieved is masking of the weak positive as a negative. Despite the utility of relieving agents and improved extraction methodology, again, such measures do not positively validate the PCR process in negative reactions, and the veracity of negative calls may remain questionable if known weak positives yield occasional negative results.

We describe and demonstrate the function of three artificial DNA IC target molecules (with their matching primers and probes) to cull false-negative calls in fluorogenic, $5^{\prime}$-exonuclease linear hydrolysis (TaqMan) assays for P. pachyrhizi and P. meibomiae (5) and Fusarium virguliforme (6) by producing a positive signal, thereby validating the PCR process. Because TaqMan chemistry utilizes fluorescent reporters having discrete spectral properties, it is amenable to multiplexing, and several assays may be combined in a single reaction vessel, each assay being independently tracked by its unique fluorescent probe. The $P$. pachyrhizi internal control (PpaIC) is a single-stranded synthetic oligonucleotide IC target, arranged as a core sequence flanked by regions complementary to the primers of the $P$. pachyrhizi assay itself, affording simplicity in reaction assembly. The $P$. meibomiae internal control (PmeIC) is a similar oligonucleotide target, having the same core sequence but flanked by regions complementary to the primers of the $P$. meibomiae assay. Both ICs are short enough to be directly synthesized at minimal cost, and both utilize the same fluorescent probe, further reducing reagent costs. The Haudenshield and Hartman internal control (HHIC) is a longer synthetic, double-stranded DNA carrying regions complementary to independent primers and a unique probe, and cloned into a plasmid for convenient production. HHIC has proven useful when multiplexed into the $F$. virguliforme assay and, as a general-purpose assay, it is not limited to any specific primary target. An abstract of preliminary results of this project has been published (9).

\section{Materials and Methods}

DNA preparation. Soybean (Glycine $\max (\mathrm{L}$.) Merr.) reference DNA was prepared as described, (3) with the following modifications: Leaf tissue of cv. Williams 82 was first lyophilized and then $1 \mathrm{~g}$ was powdered in a mortar and pestle. After resuspending the first isopropanolic precipitate, $25 \mu \mathrm{g}$ of RNase A was added and the material was incubated at $37^{\circ} \mathrm{C}$ for $30 \mathrm{~min}$. The final ethanolwashed DNA pellet was resuspended in $5 \mathrm{mM}$ Tris, $\mathrm{pH} 8$, and then extracted once with a 25:24:1 mixture of phenol/chloroform/ isoamyl alcohol (P-3803; Sigma-Aldrich, St. Louis). DNA in the aqueous phase was precipitated with ethanol and centrifuged, and the pellet was air dried. The final DNA pellet was resuspended in $10 \mathrm{mM}$ Tris and $1 \mathrm{mM}$ EDTA $(\mathrm{pH} 8)$ and a yield of $1.55 \mathrm{mg}$ of DNA was determined spectrophotometrically (Nanodrop 1000; NanoDrop Products/Thermo Fisher Scientific, Wilmington, DE). From this G. $\max$ DNA, a dilution series was prepared in a diluent (DIL; $5 \mathrm{mM}$ Tris buffer, $\mathrm{pH} \mathrm{8}$, containing sheared carrier salmon sperm DNA at $1 \mu \mathrm{g} / \mathrm{ml}$; Ambion, Austin, TX) to make $20 \mathrm{ng} / \mu \mathrm{l}, 2$ $\mathrm{ng} / \mu \mathrm{l}, 200 \mathrm{pg} / \mu \mathrm{l}, 20 \mathrm{pg} / \mu \mathrm{l}$, and $2 \mathrm{pg} / \mu \mathrm{l}$, and aliquots were dispensed and frozen at $-80^{\circ} \mathrm{C}$.

Soybean rust reference DNA was prepared from urediniospores of P. pachyrhizi isolate 07FL-1 collected from soybean leaves, heat killed at $55^{\circ} \mathrm{C}$ for $16 \mathrm{~h}$, and vigorously suspended in $0.05 \%$ (vol/vol) Tween-20 before microscopic enumeration in a hemacy- tometer. The spores were then extracted using the FastDNA Spin Kit and FastPrep FP120A instrument (MP Biomedicals, Solon, $\mathrm{OH}$ ) in eight Lysing Matrix A tubes (garnet sand and one 0.25-in. ceramic sphere) with $1 \mathrm{ml}$ of cell lysis solution-yeast (CLS-Y) extraction buffer (included with the kit) plus $1 \mu \mathrm{g}$ of salmon DNA as a carrier per tube, and homogenized for $40 \mathrm{~s}$ at a speed of $6 \mathrm{~m} / \mathrm{s}$. Eluates were pooled, chilled at $4^{\circ} \mathrm{C}$ overnight, and centrifuged at $16,000 \times g$ for $10 \mathrm{~min}$., and a clarified supernatant was recovered. Based upon volumetric recovery and the initial microscopic spore quantification, the resulting DNA solution represented 2,621 sporeequivalents (SEq) per microliter (quantification by spectrophotometry was not feasible because of the low amount of rust DNA and the presence of carrier salmon DNA). From this material, serial dilutions were prepared in DIL to make $100,10,1,0.1$, and $0.01 \mathrm{SEq} / \mu \mathrm{l}$, and aliquots were dispensed and frozen at $-80^{\circ} \mathrm{C}$. DNA of $P$. meibomiae was a provided by R. Frederick (Frederick, $\mathrm{MD}$ ), and $1 \mu \mathrm{g}$ was suspended in $5 \mathrm{mM}$ Tris, $\mathrm{pH} \mathrm{8}$; stored frozen at $-20^{\circ} \mathrm{C}$; and serially diluted with DIL to concentrations of 5,000 , $500,50,5$, and $0.5 \mathrm{pg} / \mu \mathrm{l}$, as needed.

Reference DNA of $F$. virguliforme, the soybean sudden death syndrome pathogen, was prepared from approximately $4 \mathrm{~cm}^{2}$ of dense mycelial mat of isolate MONT-1 cut from the surface of potato dextrose agar divided among three tubes and extracted using the FastDNA method above, except that no salmon DNA was added, and the tubes were homogenized twice in the FastPrep instrument with an intervening $1 \mathrm{~h}$ of incubation on ice. The FastDNA eluates were pooled $(0.75 \mathrm{ml})$ and frozen at $-20^{\circ} \mathrm{C}$. When thawed, $0.25 \mathrm{ml}$ of $5 \mathrm{M}$ ammonium acetate was added and DNA was precipitated with an equal volume of isopropanol and sedimented at $16,000 \times g$ for $10 \mathrm{~min}$. The recovered pellet was air dried and suspended in $0.5 \mathrm{ml}$ of $5 \mathrm{mM}$ Tris, $\mathrm{pH} 8$, and a concentration of $51.7 \mu \mathrm{g} / \mathrm{ml}$ was determined using the Nanodrop instrument. From this stock and using a saline diluent (S-DIL; DIL plus $1 \mathrm{mM} \mathrm{NaCl}$ ), a dilution series was prepared at $10^{6}, 10^{5}, 10^{4}, 10^{6}$, 100 , and $10 \mathrm{fg} / \mu \mathrm{l}$.

When extracting $P$. pachyrhizi DNA from dry leaf tissue, $12 G$. max leaflets showing heavy sporulation by $P$. pachyrhizi (collected in Vietnam during 2008 and heat killed for $12 \mathrm{~h}$ at $50^{\circ} \mathrm{C}$; provided by T. A. Pham) were ground in a mortar and pestle to produce a fine powder. Samples $(50 \mathrm{mg})$ of this powder were placed in each extraction tube with $1 \mathrm{ml}$ of CLS-Y (or $0.8 \mathrm{ml}$ of CLS-VF with 0.2 $\mathrm{ml}$ of protein precipitation solution [PPS]) extraction buffer as supplied with the FastDNA kit and processed according to the method above, except that no salmon DNA was added. The tubes were homogenized twice in the FastPrep instrument with an intervening $1 \mathrm{~h}$ of incubation on ice. After elution and storage overnight at $4^{\circ} \mathrm{C}$, approximately $80 \mu \mathrm{l}$ of clarified supernatant was recovered. To observe the impact of any inhibitors on quantification, the DNAs were diluted 1:20 and 1:100 with DIL, and bovine serum albumin (BSA) was added to the reactions where the 1:100 dilutions were assayed. When extracting DNA from archival tissue, samples of approximately $1 \mathrm{~cm}^{2}$ exhibiting uredinia were taken from specimens provided by J. Hennen: "SR-1" ( $P$. pachyrhizi on G. max, collected in Taiwan 1983) and "SR-4" (P. meibomiae on G. max, collected in Brazil, 1986). The leaf samples were placed directly into extraction tubes and processed as for powdered leaf tissue, using the CLS-VF/PPS extraction buffers, and the $80 \mu \mathrm{l}$ of clarified supernatant was used either undiluted or with a 1:10 dilution in DIL.

PpaIC and PmeIC. An arbitrary core sequence of 42 nucleotide (nt) residues was designed for hybridization to a 25-base oligonucleotide probe (Core-Cy5; 5' Cy5-labeled and $3^{\prime}$ IowaBlackquenched) at a $\mathrm{T}_{\mathrm{m}}$ similar to that of the probe used in the P. pachyrhizi and P. meibomiae assays (SBR-FAM; 5' FAM-labeled and 3' IowaBlack-quenched), and flanked by primer-binding sequences complementary to the primers for those same assays (Ppm1 and Ppa2 for $P$. pachyrhizi, or Ppm1 and Pme2 for P. meibomiae) creating 87- and 85-nt targets, respectively (Table 1). $\mathrm{T}_{\mathrm{m}} \mathrm{s}$ were calculated using the VectorNTI 7 software package, (Invitrogen, Carlsbad, CA) and the OligoAnalyzer 3.1 internet application 
(Integrated DNA Technologies [IDT], Coralville, IA). These oligonucleotide targets were synthesized commercially, with additional polyacrylamide gel electrophoresis (PAGE) purification provided by the vendor (IDT). Based upon the yield determined by the vendor, a $1 \mathrm{fM}$ working stock $(600 \mathrm{copies} / \mu \mathrm{l})$ was prepared in DIL.

HHIC. An artificial insert sequence was constructed, carrying unique primer and probe hybridization sequences having $\mathrm{T}_{\mathrm{m}} \mathrm{s}$ compatible with the $P$. pachyrhizi assay (Table 1). A 23-nt $5^{\prime}$ HEX-labeled, 3' IowaBlack-quenched probe was utilized. The insert sequence was commercially synthesized (IDT) as two partially complementary (shown below in italics) oligonucleotides (73 and 78 nt), with purification by PAGE: 5'-CACGCCTAGG ACGAGAACTC CCACATCGAG CTTGACGCAA ACGACCACGC CAGGACCATG GCAAACATCA ACA-3' and 5'-CAATCAGCGG GTGTTTCAGC ACAAGGCGTT GCGCTCGGTG TTGATGTTTG CCATGGTCCT GGCGTGGTCG TTTGCGTC-3'. The two oligonucleotides were annealed to one another and made doublestranded using the Klenow Fill-In Kit (Stratagene, La Jolla, CA). The full-length 111-bp fragment was purified with the QIAquick PCR spun column kit (Qiagen, Valencia, CA), cloned, and transformed into Escherichia coli for production, using the StrataClone Blunt PCR Cloning Kit (Stratagene). A single colony containing the insert was selected, its plasmid was purified by alkaline lysis (22), and the identity of the insert was confirmed by sequencing (W. M. Keck Biotechnology Center, University of Illinois). The sequence of the 3,580-bp plasmid, pJSH-B14, was analyzed using the NEBcutter internet application (New England Biolabs, Ipswich, MA) to identify a unique restriction site $(X m n I)$ present only in the backbone of the plasmid. After linearization with XmnI (New England Biolabs), the double-stranded DNA was repurified using the QIAquick PCR spun column kit, and a spectrophotometric estimate of concentration was made. Based upon a calculated molecular mass estimate of $2,300 \mathrm{kDa}$, a solution of $\mathrm{pJSH}-\mathrm{B} 14$ at approximately $10^{6}$ copies/ $\mu$ l was prepared in S-DIL, and then further diluted to approximately 0.2 copies $/ \mu 1$. In all, 90 replicate 5- $\mu \mathrm{l}$ samples were drawn and amplified by Q-PCR for 45 cycles to make a determination of actual copy concentration, based upon the fraction of negative reactions and utilizing Poisson statistical analysis $(7,21,23)$. A 1-fM working stock was prepared in S-DIL for use as an IC. pJSH-B14 was deposited as Addgene plasmid 20145; the sequence and culture are available at http://www. addgene.org/Glen_Hartman (or directly from the authors).

GmGAPDH and $\boldsymbol{F}$. virguliforme assays. As a measure of the amount of amplifiable genomic G. $\max$ DNA recovered from soybean tissues, a novel Q-PCR assay for the endogenous housekeeping gene glyceraldehyde-3-phosphate dehydrogenase (GAPDH) was developed and optimized for multiplexing under our amplification conditions (data not shown), using the G. max GAPDH sequence available in GenBank (accession number AF061564). The primers and 5' HEX-labeled, 3' IowaBlack-quenched probe (Table 1) were synthesized by IDT, and they were used at the following final concentrations: GmG-14F and GmG-14R, $600 \mathrm{nM}$; GmG-14HEX, 200 nM. A dilution series of G. max DNA (quantified by Nanodrop) yielded a linear standard curve in the range of $100 \mathrm{ng}$ to $10 \mathrm{pg}$ per reaction. A further dilution toward extinction ( $1 \mathrm{pg}$ /assay) with 95 replicates and a Poisson statistical analysis (data not shown) indicated a concentration of 1.26 target molecules per picogram of DNA and thus, assuming an estimated genome size of $950 \mathrm{Mbp}$, a single-copy gene for the assay. To test the functionality of the HHIC control in the context of a Q-PCR assay for a nonrust soybean pathogen, that of $F$. virguliforme was selected (6). The primers (Table 1 ) were synthesized by IDT and the $5^{\prime}$ FAMlabeled, $3^{\prime}$ MGB-quenched probe (Table 1) by Applied Biosystems, and they were used at the following final concentrations: Fsg-q- $1 \mathrm{~F}$ and Fsg-q-1R, $900 \mathrm{nM}$; Fsg-q-1FAM, $200 \mathrm{nM}$. In F. virguliforme assays, the same cycling conditions were used as for $P$. pachyrhizi, except the final concentration of $\mathrm{MgCl}_{2}$ was $3 \mathrm{mM}$, as provided by the Invitrogen Supermix without adjustment.

Q-PCR conditions. Platinum Quantitative PCR SuperMix-UDG (Invitrogen) was used for all amplifications, in a Stratagene MX3005P real-time thermal cycler. A $25-\mu l$ reaction volume was prepared and the following thermal profile was employed: 2 min at $60^{\circ} \mathrm{C}, 2 \mathrm{~min}$ at $95^{\circ} \mathrm{C}$, and 40 cycles of $15 \mathrm{~s}$ at $95^{\circ} \mathrm{C}$ and $30 \mathrm{~s}$ at $60^{\circ} \mathrm{C}$. Cycle threshold values were determined using the adaptive baseline or automatic threshold settings of the instrument, with filter gain settings adequate to keep fluorescence detection within the dynamic range of the sensor. A reference DNA dilution series was used to compare results among samples as needed, and between runs. ROX reference dye was included at $50 \mathrm{nM}$ and $\mathrm{MgCl}_{2}$

Table 1. Primers, probes, and internal control target DNA sequences used in this study ${ }^{\mathrm{a}}$

\begin{tabular}{|c|c|c|c|}
\hline Name & $\mathbf{T}_{\mathbf{m}} \mathbf{b}^{2}$ & $\mathbf{T}_{\mathrm{m}}{ }^{\mathrm{c}}$ & Sequence \\
\hline $\mathrm{Ppm}^{\mathrm{d}}$ & 52.2 & 62.5 & GCAGAATTCA GTGAATCATC AAG \\
\hline $\mathrm{Ppa} 2^{\mathrm{d}}$ & 52.4 & 63.1 & GCAACACTCA AAATCCAACA AT \\
\hline$P m e 2^{d}$ & 52.8 & 62.8 & GCACTCAAAA TCCAACATGC \\
\hline HHIC-Fwd & 55.7 & 65.9 & CTAGGACGAG AACTCCCACA T \\
\hline HHIC-Rev & 53.1 & 62.2 & CAATCAGCGG GTGTTTCA \\
\hline GmG-14F & 55.0 & 65.2 & CATCGGAGGG AAGTATGAAA GG \\
\hline GmG-14R & 54.5 & 64.9 & GTACAATGCA TGATGGTGGC \\
\hline Fsg-q-1Fe & 55.7 & 65.7 & GATACCCAAG TAGTCTTTGC AGTAAATG \\
\hline Fsg-q-1Re & 55.5 & 65.8 & TTAATGCCTA GTCCCCTATC AACAT \\
\hline SBR-FAM ${ }^{\mathrm{d}}$ & 59.0 & 67.5 & FAM-CCAAAAGGTA CACCTGTTTG AGTGTCA-IBFQ \\
\hline Core-Сy5 & 60.1 & 68.2 & Cy5-TGCTTAGGAC GAGAACTCCC ACATC-IBRQ \\
\hline HHIC-HEX & 59.6 & 68.8 & HEX-TCGGTGTTGA TGTTTGCCAT GGT-IBFQ \\
\hline GmG-14HEX & 59.7 & 68.5 & HEX-TTTGTGGGTG ACAACAGGTG ATGG-IBFQ \\
\hline Fsg-q-1FAM & 50.6 & 58.8 & FAM-TGAATGCCAT AGGTCAGAT-MGBNFQ \\
\hline \multirow[t]{2}{*}{ PpaIC } & & & GCAGAATTCA GTGAATCATC AAGCATGCTT AGGACGAGAA CTCCCACATC GAGCTGGACA \\
\hline & 71.1 & $77.1^{\mathrm{g}}$ & TCTGCATTGT TGGATTTTGA GTGTTGC \\
\hline \multirow[t]{2}{*}{ PmeIC $^{\mathrm{f}}$} & & & GCAGAATTCA GTGAATCATC AAGCATGCTT AGGACGAGAA CTCCCACATC GAGCTGGACA \\
\hline & 71.6 & $77.2^{\mathrm{g}}$ & TCTGCGCATG TTGGATTTTG AGTGC \\
\hline \multirow[t]{2}{*}{$\mathrm{HHIC}^{\mathrm{f}, \mathrm{h}}$} & & & CACGCCTAGG ACGAGAACTC CCACATCGAG CTTGACGCAA ACGACCACGC CAGGACCATG \\
\hline & 73.7 & $78.7^{\mathrm{g}}$ & GCAAACATCA ACACCGAGCG CAACGCCTTG TGCTGAAACA CCCGCTGATT G \\
\hline
\end{tabular}

a All were resuspended and stored in $5 \mathrm{mM}$ Tris, $\mathrm{pH} 8$.

${ }^{\text {b }}$ Utilizing default specifications: $50 \mathrm{mM} \mathrm{Na}{ }^{+}, 0.25 \mu \mathrm{M}$ oligonucleotide, no $\mathrm{Mg}^{++}$, no dNTPs

${ }^{c}$ Specifying $50 \mathrm{mM} \mathrm{Na}+, 0.25 \mathrm{mM}$ dNTPs, and the concentration of $\mathrm{Mg}^{++}$and oligonucleotide used in the assay.

d Sequence given by Frederick et al. (5).

${ }^{\text {e }}$ Sequence given by Gao et al. (6). Stabilization by the MGBNFQ affects $\mathrm{T}_{\mathrm{m}}$, but is not considered here.

${ }^{\mathrm{f}}$ Primer-binding regions underlined, probe-binding regions double-underlined.

$\mathrm{g}$ Assuming $0.1 \mathrm{nM}$ oligonucleotide, and for the sequence of the amplicon only.

${ }^{\text {h }}$ Sequence of the HHIC construct only, carried by pJSH-B14. 
was adjusted to a final concentration of $7 \mathrm{mM}$. Primers for PpaIC and PmeIC were added to a final concentration of $300 \mathrm{nM}$ and SBR-FAM was used at a final concentration of $100 \mathrm{nM}$ (5), whereas the HHIC primers and both IC probes were used at empirically determined, optimal (data not shown) concentrations as follows: HHIC-Fwd, $600 \mathrm{nM}$; HHIC-Rev, $200 \mathrm{nM}$; HHIC-HEX, $200 \mathrm{nM}$; and Core-Cy5, $150 \mathrm{nM}$. Then, 50 ymole (30 copies) of IC target was added to each reaction. When BSA (Fraction V; Fisher Scientific, Pittsburgh) was included to relieve inhibition, it was at a final concentration of $400 \mathrm{ng} / \mu \mathrm{l}$. All reagents, excluding test DNA and test inhibitors, were combined as a cocktail with sufficient water to bring the volume to $15 \mu \mathrm{l}$, then dispensed into reaction tubes containing $10 \mu \mathrm{l}$ of test DNA (plus water or test inhibitors). When inhibitors were spiked into Q-PCR reactions, they were prepared as a $5 \times$ solution in $5 \mathrm{mM}$ Tris, $\mathrm{pH} 8$, and added to the reaction tube to make the following final concentrations: 20 and $4 \mathrm{mM}$ EDTA (E7889; Sigma-Aldrich); sodium dodecyl sulfate (SDS; BP166; Fisher Scientific); pectin (citrus; P-9135; Sigma-Aldrich); and xylan (beechwood; X4252, Sigma-Aldrich) at 100 and $20 \mu \mathrm{g} / \mathrm{ml}$; and humic acid (sodium salt; H16752; Sigma-Aldrich) at 2 and 0.4 $\mu \mathrm{g} / \mathrm{ml}$. Aerosol-resistant pipette tips and nucleic acid-free, DNasefree molecular biology-grade reagents and water were used throughout, to reduce the potential for contamination. Low-binding microcentrifuge tubes and pipette tips reduced the potential for DNA loss. Statistical analyses were conducted using the generalized linear model (PROC GLM in SAS 9.1.3; SAS Institute, Cary, $\mathrm{NC})$.

Interference testing. Serial dilutions of DNA from P. pachyrhizi and $P$. meibomiae established standard curves representing the performance of those assays in our laboratory. To test for potential interference of the Ppa and Pme assays by the components of the IC reactions, parallel standards were assayed to which were added $5 \mu \mathrm{l}$ of (i) $0.01 \mathrm{fM}$ PpaIC (target only), (ii) $0.01 \mathrm{fM}$ PmeIC (target only), (iii) $10 \mathrm{fM}$ pJSH-B14 (linearized plasmid target only), (iv) 1 $\mu \mathrm{M}$ Core-Cy5 (probe only), (v) $1 \mu \mathrm{M}$ HHIC-HEX probe $+3 \mu \mathrm{M}$ HHIC-Fwd primer $+1 \mu \mathrm{M}$ HHIC-Rev primer, and (vi) functional IC reaction for $P$. pachyrhizi or $P$. meibomiae, according to the primary target being assayed. To assess the potential of the HHIC reaction as a universal internal control, it was included as a multiplexed reaction in an assay for an unrelated soybean pathogen, $F$. virguliforme. Serial dilutions of DNA from $F$. virguliforme were used to establish a standard curve representing the performance of that assay. To a comparable dilution series, the pJSH-B14 target, primers, and probe were included. In similar experiments, the independent HHIC assay was tested for interference by components of the P. pachyrhizi, P. meibomiae, PpaIC, and PmeIC reactions. A dilution series of linearized pJSH-B14 was prepared as a reference standard to create a standard curve of $10^{5}, 10^{4}, 10^{3}, 10^{2}$, and 10 copies of the target. To parallel reactions, $5 \mu \mathrm{l}$ of the following mixtures were added: (i) $1 \mu \mathrm{M}$ Core-Cy5 (probe only), (ii) $1.5 \mu \mathrm{M}$

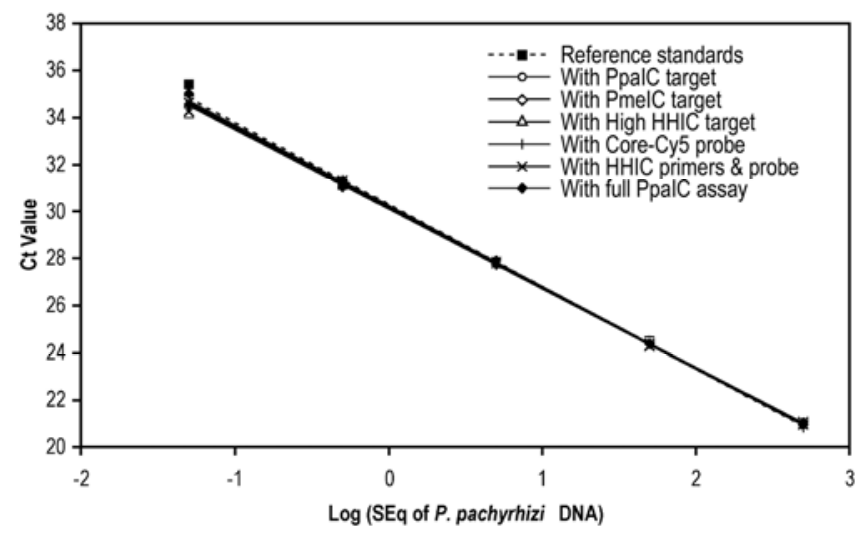

Fig. 1. Noneffect of internal control reagents on Phakopsora pachyrhizi standard curve. Least-squares best-fit line is drawn for each; slope, y-intercept, $R^{2}$, and standard errors are given in Table $2 . C_{t}=$ cycle threshold. each of primers (Ppm1, Ppa2, and Pme2) + $0.5 \mu \mathrm{M}$ SBR-FAM probe, and (iii) $10 \mathrm{fM}$ each of PpaIC target and PmeIC target.

Recovery estimations. Two extraction buffers were utilized to compare the extraction efficiency and assess the presence of inhibitors from leaf specimens: CLS-Y and CLS-VF. Samples of rustinfected, heat-killed, powdered leaf tissue were extracted from five replicates using each of the buffers. Each replicate had been spiked with $2.6 \times 10^{5}$ copies of linearized pJSH-B14 from a stock solution that was also used to prepare a standard curve; thus, there were three different DNA types present: pathogen ( $P$. pachyrhizi), tracer (pJSH-B14), and host (G. max). Three Q-PCR assays were (separately) performed on these samples: $P$. pachyrhizi, to compare the yield of fungal DNA from plant tissue with either of the two extraction buffers; HHIC, to assess the overall efficiency of DNA recovery between the two buffers; and $G m \mathrm{GAPDH}$, to compare the yield of plant DNA using the two buffers. The extractives were diluted 1:20 and assayed without BSA or diluted 1:100 and assayed with added BSA.

\section{Results}

In TaqMan Q-PCR, the kinetics of DNA amplification are observable during the PCR process by virtue of an increase in fluorescence caused by probe hydrolysis, paralleling the amount of amplicon generated, eventually entering the dynamic range of detection of the Q-PCR instrument, and finally crossing the threshold of detection (over background). The number of thermal cycles required to surpass this threshold is termed the $C_{t}$, and is a logarithmic function of the number of initial copies of the target amplicon; for example, if 8,000 initial copies results in a $C_{t}$ value of 27 , then 1,000 initial copies will result in a $C_{t}$ value of 30 . In serial dilutions, we found that the linearity of this relationship often exceeded a coefficient of correlation $\left(R^{2}\right)$ of 0.98 ; typically, 0.99 or better.

The internal control assays did not interfere with the performance of the primary assays. A standard curve prepared from serial dilutions of DNA from $P$. pachyrhizi and $P$. meibomiae was not affected by the components of the IC reactions (Figs. 1 and 2). When utilized as a exogenous internal control for the $F$. virguliforme assay, the HHIC assay components similarly exhibited no impact. In every case, there was no significant $(P>0.13)$ difference among the standard curve and the test assays (slope, intercept, and linearity; Table $2 \mathrm{~A}$ to $\mathrm{C}$ ), indicating no interference with the primary assay.

Similarly, none of the rust primers, rust FAM probe, or IC targets had a statistically significant $(P>0.3)$ impact on the standard curve of the HHIC assay (Table 2D; Fig. 3), indicating no interference. In the presence of Core-Cy5 probe, the sensitivity of the HHIC assay was significantly $(P<0.0001)$ decreased by a factor of 10 (the y-intercept was increased by 3.5 cycles), although slope and linearity were maintained (Table 2D; Fig. 3).

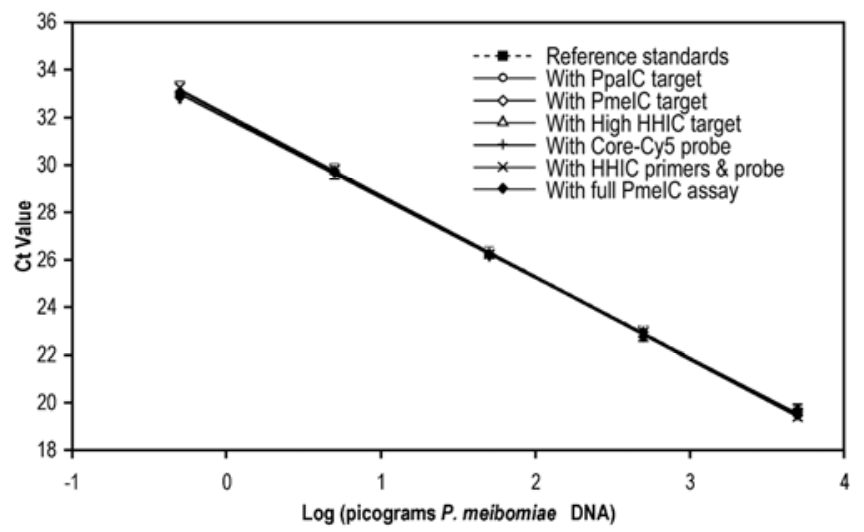

Fig. 2. Noneffect of internal control reagents on Phakopsora meibomiae standard curve. Least-squares best-fit line is drawn for each; slope, y-intercept, $R^{2}$, and standard errors are given in Table 2. $C_{t}=$ cycle threshold. 
The PpaIC and PmeIC reactions were intended to be qualitative rather than quantitative; because the IC targets were present in very low amounts (30 copies per reaction), they were expected to yield $\mathrm{C}_{\mathrm{t}}$ values of approximately 35 in true-negative reactions and no $\mathrm{C}_{\mathrm{t}}$ value in false-negative reactions. Because the Core-Cy5 probe for those reactions exhibited a moderate suppression on amplification of the HHIC amplicon, it was possible that adventitious presence of the pJSH-B14 target might have an inhibitory effect on the IC reaction. A test was performed to confirm that presence of the pJSH-B14 target (30,000 copies/reaction) would not affect the kinetics of amplification of the PpaIC and PmeIC targets when they were assayed as a dilution series (data not shown).

PpaIC and PmeIC reactions effectively validated true negatives and identified false negatives in the presence of PCR-inhibitory agents. Two commonly employed methods of overcoming the effects of PCR inhibitors are dilution of the sample (and, thus, any intrinsic inhibitor) and addition of relieving agents such as BSA. The PpaIC reaction was functionality tested to discriminate between true and false negatives in a $P$. pachyrhizi assay containing several commonly found inhibitors, and with attempted relief by dilution of the inhibitor, addition of BSA, or both dilution and BSA. The inhibitors tested were EDTA, humic acid, pectin, xylan, and SDS. Because the IC target was present in such low amounts, the primary assay frequently dominated the amplification in positive reactions where inhibition was absent; the true-negative status of a control reaction was validated by amplification of the IC in the absence of inhibitors (Fig. 4A). The inhibitory effect of 20 $\mathrm{mM}$ EDTA or SDS at $100 \mathrm{ppm}$ was observed to be relieved by 1:5 dilution but not by the addition of BSA (Fig. 4B and C), which remained falsely negative. In contrast, the false-negative result induced by humic acid at $2 \mathrm{ppm}$ was not corrected by 1:5 dilution but was clearly positive when BSA was added (Fig. 4D). Pectin was found to partially inhibit Q-PCR when present at $100 \mathrm{ppm}$ and, whereas dilution at 1:5 resulted in substantial relief, the inclusion of BSA was ineffective (Fig. 4E). The false-negative result observed when xylan was included at $100 \mathrm{ppm}$ was corrected by either 1:5 dilution or by addition of BSA (Fig. 4F). Similar find- ings were observed in a parallel assay for $10 \mathrm{pg}$ of $P$. meibomiae DNA, using the PmeIC reaction (data not shown).

PpaIC and PmeIC confirmed the diagnostic results for $P$. pachyrhizi and $P$. meibomiae in preserved specimens. Dried soybean leaf specimens infected with soybean rust (SR-1 and SR4) were extracted and the results of Q-PCR diagnoses were compared with the reported identities of the fungi as determined by classical means. A serial dilution of purified reference DNA from $P$. pachyrhizi and P. meibomiae was used to assess performance of the assay with and without added BSA (Fig. 5A and B), and to establish a standard curve to quantify the yield of any fungal DNA isolated (data not shown). At the concentration used, despite the formation of a visible precipitate in the reaction tube during the PCR cycling, BSA had no impact on the amplification curves of

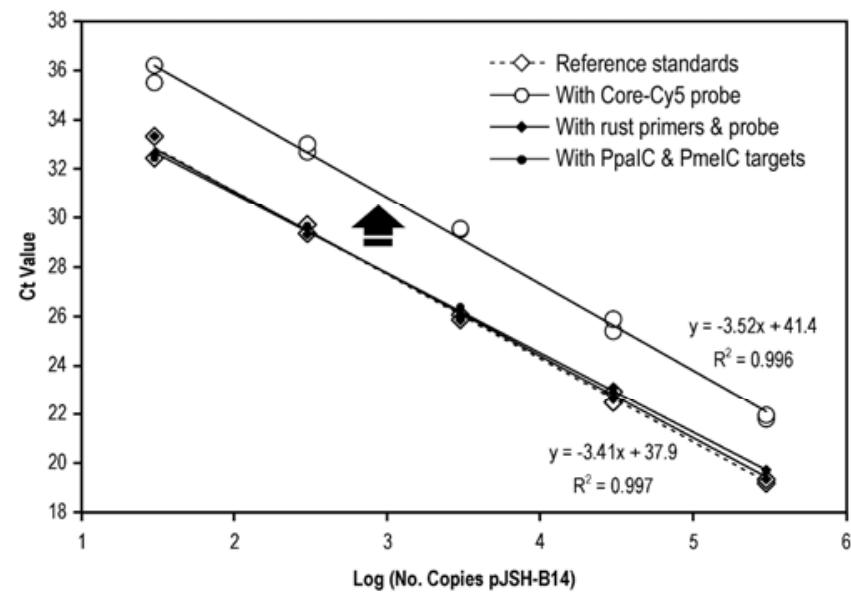

Fig. 3. Effect of Core Cy5 probe on Haudensheild and Hartman internal control (HHIC) assay with pJSH-B14 dilution series standard curve. Least-squares best fit line equation is shown for the reference standards (lower) and the result with Core Cy5 probe (upper); slope, y-intercept, $R^{2}$, and standard errors are given in Table 2. $\mathrm{C}_{\mathrm{t}}=$ cycle threshold.

Table 2. Impact of internal control reagents on standard curves of assays for Phakopsora pachyrhizi, P. meibomiae, Fusarium virguliforme, and pJSH-B14 DNA $^{\mathrm{a}}$

\begin{tabular}{|c|c|c|c|c|c|c|}
\hline Assay & Treatment & Slope (m) & $\mathbf{s e}_{\mathrm{m}} \mathbf{b}$ & Intercept (b) & $\mathbf{s e}_{b}{ }^{c}$ & $R^{2}$ \\
\hline \multicolumn{7}{|l|}{ A } \\
\hline P. pachyrhizi & None & -3.49 & 0.06 & 30.3 & 0.09 & 0.998 \\
\hline P. pachyrhizi & PpaIC target ${ }^{\mathrm{d}}$ & -3.44 & 0.03 & 30.2 & 0.05 & 0.999 \\
\hline P. pachyrhizi & PmeIC target ${ }^{\mathrm{d}}$ & -3.40 & 0.02 & 30.2 & 0.03 & 1.000 \\
\hline P. pachyrhizi & High pJSH-B14 target $^{\mathrm{e}}$ & -3.39 & 0.03 & 30.1 & 0.05 & 0.999 \\
\hline P. pachyrhizi & Core-Cy 5 probe & -3.43 & 0.03 & 30.2 & 0.06 & 0.999 \\
\hline P. pachyrhizi & HHIC primers \& HEX probe & -3.37 & 0.03 & 30.1 & 0.05 & 0.999 \\
\hline P. pachyrhizi & Functional PpaIC reaction & -3.44 & 0.03 & 30.2 & 0.05 & 0.999 \\
\hline \multicolumn{7}{|l|}{$\mathrm{B}$} \\
\hline P. meibomiae & None & -3.41 & 0.04 & 32.1 & 0.09 & 0.999 \\
\hline P. meibomiae & PpaIC target ${ }^{\mathrm{d}}$ & -3.37 & 0.03 & 32.0 & 0.07 & 0.999 \\
\hline P. meibomiae & PmeIC target ${ }^{\mathrm{d}}$ & -3.36 & 0.02 & 32.0 & 0.05 & 1.000 \\
\hline P. meibomiae & High pJSH-B14 target $^{\mathrm{e}}$ & -3.43 & 0.02 & 32.1 & 0.04 & 1.000 \\
\hline P. meibomiae & Core-Cy 5 probe & -3.38 & 0.02 & 32.0 & 0.05 & 1.000 \\
\hline P. meibomiae & HHIC primers \& HEX probe & -3.42 & 0.02 & 32.2 & 0.04 & 1.000 \\
\hline P. meibomiae & Functional PmeIC reaction & -3.36 & 0.03 & 32.0 & 0.06 & 0.999 \\
\hline \multicolumn{7}{|l|}{$\mathrm{C}$} \\
\hline$F$. virguliforme & None & -3.35 & 0.04 & 32.7 & 0.13 & 1.000 \\
\hline$F$. virguliforme & High pJSH-B14 target $^{\mathrm{e}}$ & -3.32 & 0.03 & 32.7 & 0.09 & 0.999 \\
\hline F. virguliforme & Functional HHIC reaction & -3.34 & 0.02 & 32.7 & 0.05 & 1.000 \\
\hline \multicolumn{7}{|l|}{ D } \\
\hline HHIC & None & -3.41 & 0.06 & 37.9 & 0.24 & 0.997 \\
\hline HHIC & Core-Cy5 probe & -3.52 & 0.08 & 41.4 & 0.31 & 0.996 \\
\hline HHIC & Ppm1, Ppa2, Pme 2 primers \& SBR-FAM probe & -3.35 & 0.07 & 37.8 & 0.25 & 0.997 \\
\hline HHIC & PpaIC \& PmeIC targets ${ }^{\mathrm{d}}$ & -3.24 & 0.04 & 37.5 & 0.15 & 0.999 \\
\hline
\end{tabular}

${ }^{a}$ Cycle threshold $=m\left(\log _{10}\right.$ [quantity $\left.]\right)+b$.

b Standard error of the slope.

c Standard error of the y-intercept.

${ }^{\mathrm{d}} N=30$ copies per reaction.

e $N=30,000$ copies per reaction. 
the reference DNA in either the $P$. pachyrhizi or $P$. meibomiae assay (Fig. 5A and B), and indistinguishable standard curves were produced. DNA extracted from both specimens was not initially amplified by an assay for P. pachyrhizi (Fig. 5C1 and D1); however, the failure of the PpaIC to amplify in those reactions suggested the presence of a residual PCR inhibitor contaminating the DNA preparation. When diluted 1:10, or when BSA was added, this inhibition was overcome in extracts from specimen SR-1, and amplification indicated the presence of $P$. pachyrhizi DNA (Fig. $5 \mathrm{C} 2$ to 4); whereas, for extracts from specimen SR-4, dilution (but not BSA alone) overcame the inhibition, and the IC reaction yielded a positive signal in the absence of amplification of the primary target (Fig. 5D2 to 4), confirming its status as a true negative (i.e., as not containing DNA from $P$. pachyrhizi). Similarly, when assayed for $P$. meibomiae, DNA extracted from both specimens was not initially amplified (Fig. 5E1 and F1), and the failure of the

\section{A. Control amplification reactions}
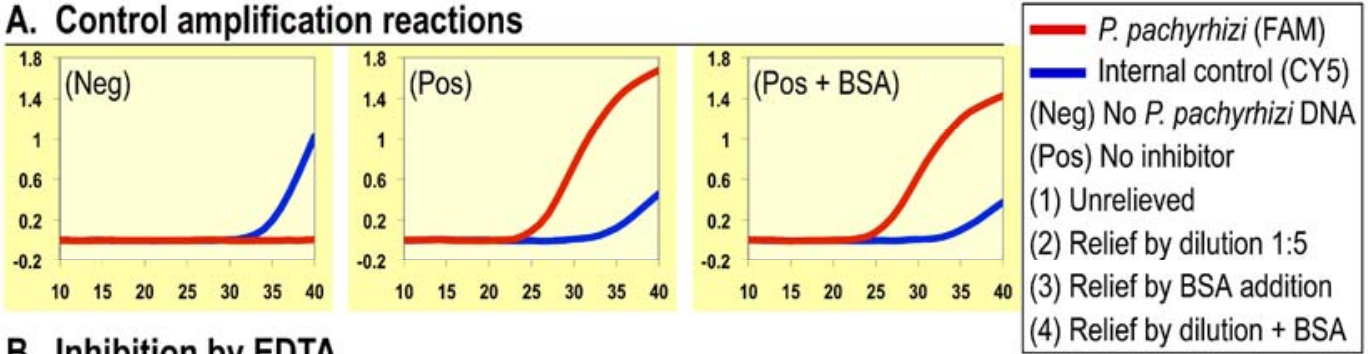

B. Inhibition by EDTA
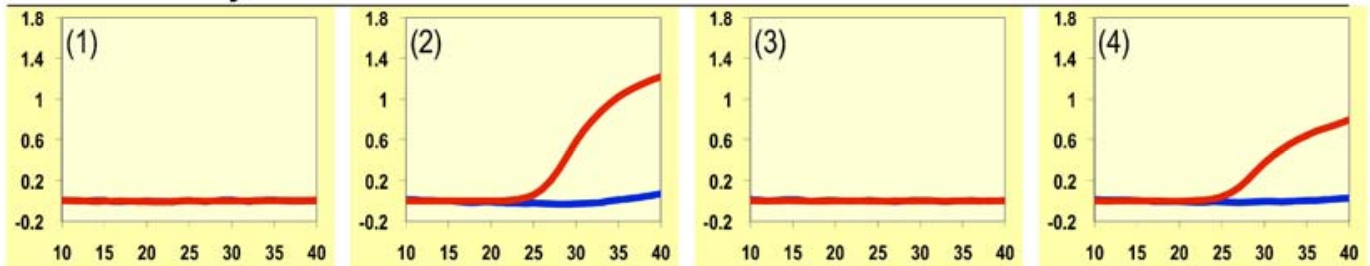

\section{Inhibition by SDS}
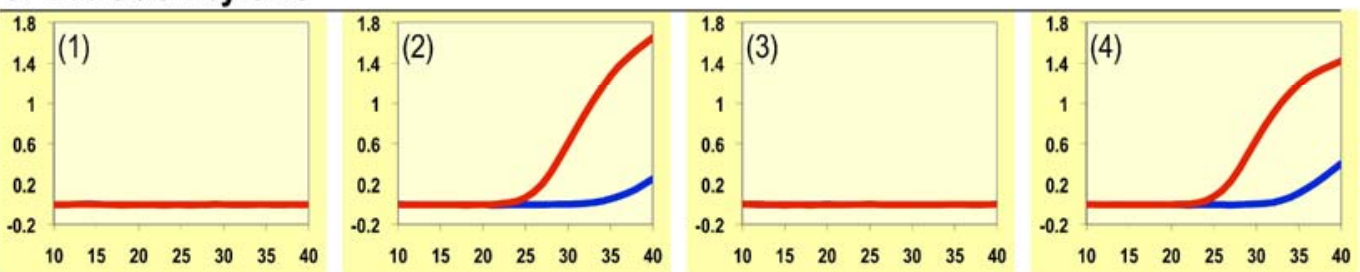

\section{Inhibition by humic acid}
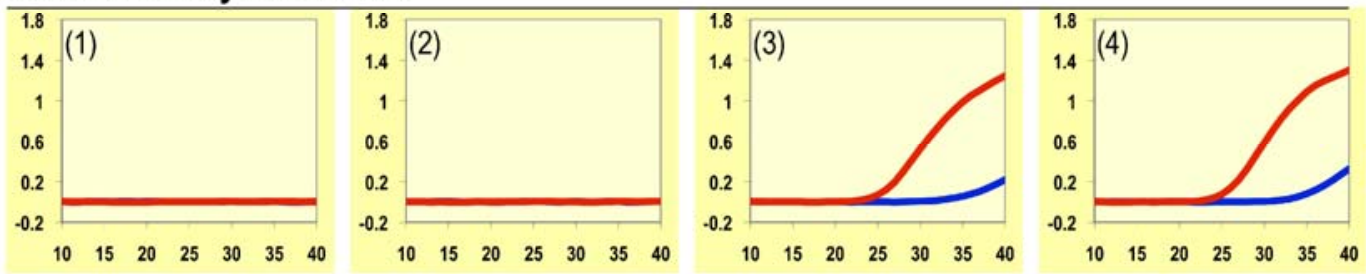

\section{E. Inhibition by pectin}
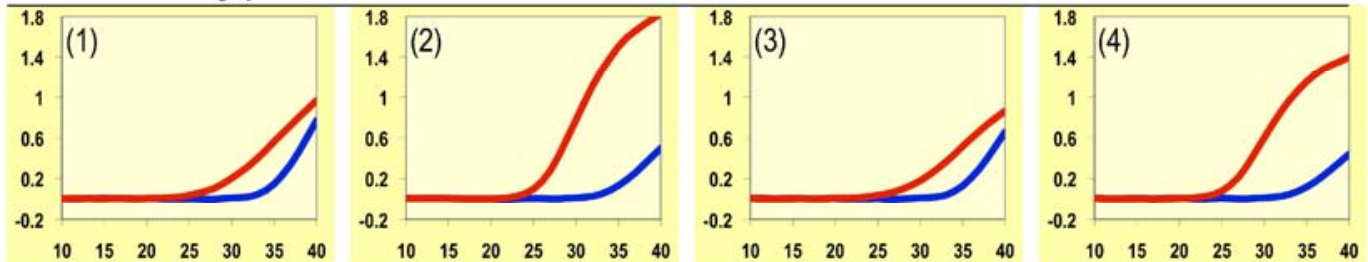

\section{F. Inhibition by xylan}
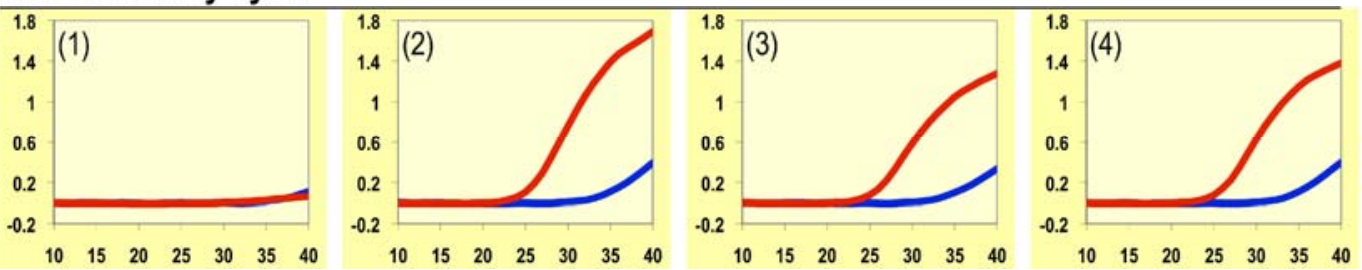

Fig. 4. Detection of false-negative results and relief of polymerase chain reaction(PCR) inhibition by bovine serum albumin (BSA) added to the reaction mixture, or by dilution of the inhibitory compound. Phakopsora pachyrhizi DNA (5 spore-equivalents) was added to each reaction, along with 30 copies of the PpalC target and test inhibitor EDTA (20 and $4 \mathrm{mM}$ ); humic acid (2 and $0.4 \mathrm{ppm}$ ); and pectin, xylan, and sodium dodecyl sulfate (SDS) (100 and $20 \mathrm{ppm}$ ). Abscissa, number of PCR cycles; ordinate, fluorescence (derivative, relative to ROX reference [not shown]). Data shown are averages of two reactions. 
PmeIC to amplify in those analyses again reflected false-negative results. When diluted 1:10 or when BSA was added, amplification of the IC but not the primary target in extraction of specimen SR-1 (Fig. 5E2 to 4) confirmed its status as a true negative (i.e., as not containing DNA from $P$. meibomiae). In contrast, dilution of (but not addition of BSA to) extracts of specimen SR-4 exhibited successful amplification of P. meibomiae, the primary target (Fig. 5F2 to 4$)$. The observation that an unidentified inhibitor, relievable by
BSA, was present in the extract of specimen SR-1 and not SR-4 is an example of the unpredictability of inhibition and the unreliability of a single relief method to overcome such inhibition in actual biological samples. These diagnostic results were in complete agreement with the previous determinations of pathogen identity made by classical microscopic observation.

pJSH-B14 functioned as a tracer DNA in evaluating purification recoveries with the HHIC assay. When the extracts were
A. P. pachyrhizi

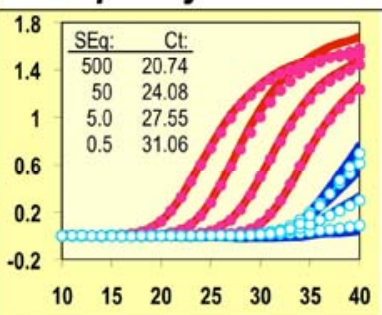

\section{B. P. meibomiae}

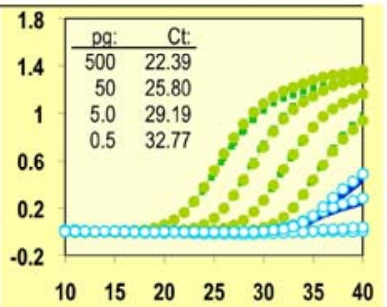

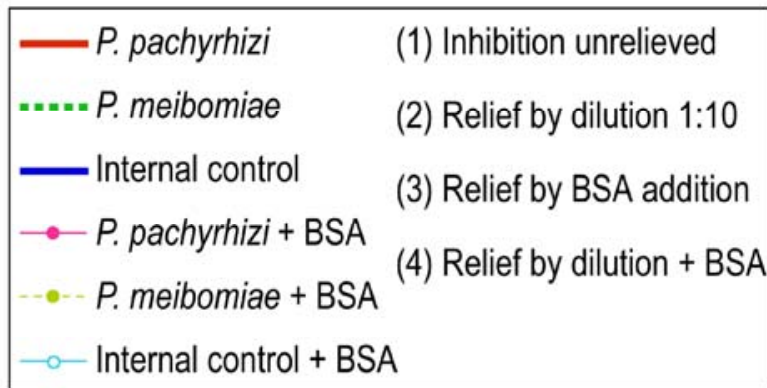

C. Specimen SR-1, assayed for P. pachyrhizi
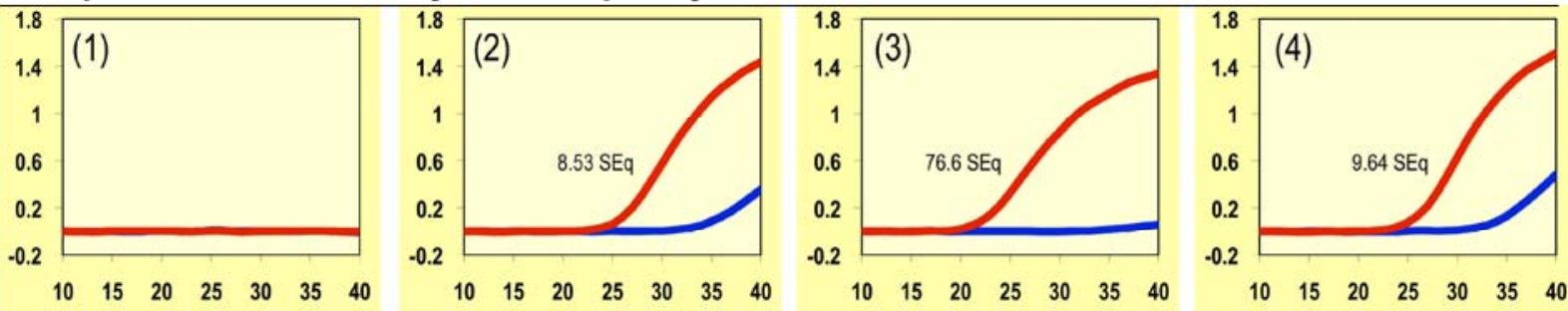

\section{Specimen SR-4, assayed for P. pachyrhizi}

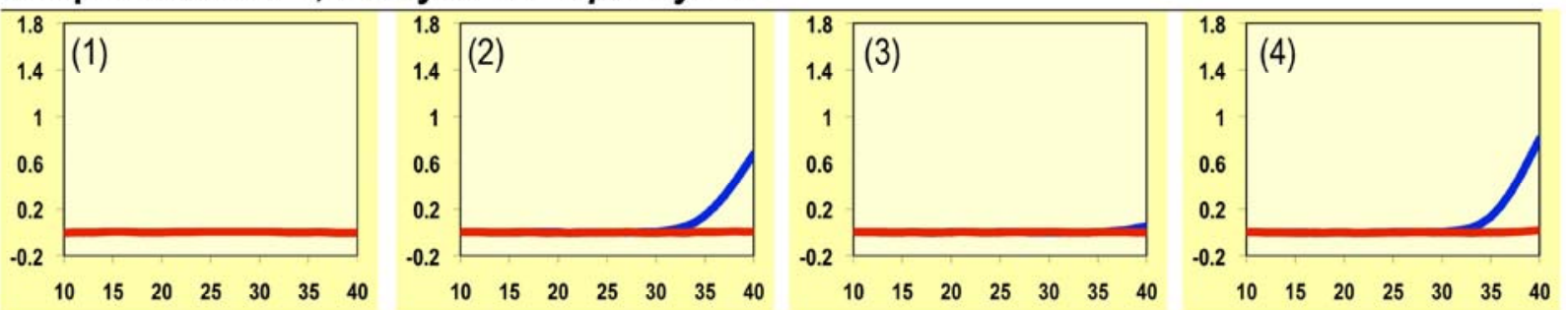

\section{E. Specimen SR-1, assayed for P. meibomiae}
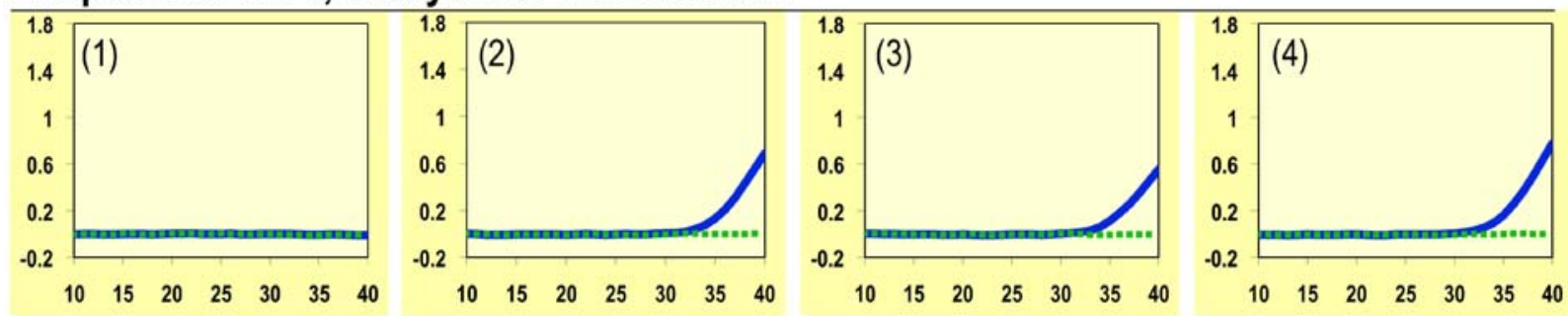

\section{F. Specimen SR-4, assayed for P. meibomiae}
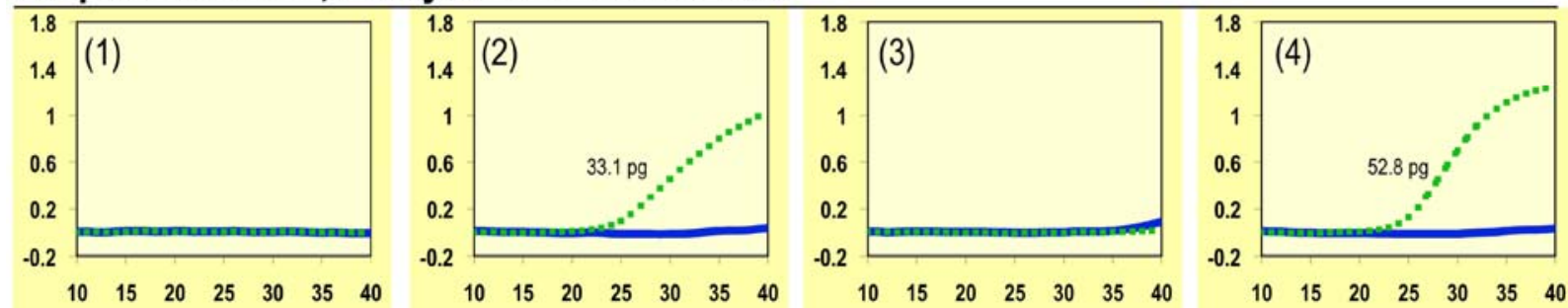

Fig. 5. Detection of false-negative results and relief of polymerase chain reaction (PCR) inhibition in extracts of archival leaves by sample dilution or with bovine serum albumin (BSA) added to the reaction mixture. A, Reactions contained 500, 50, 5.0, or 0.5 spore-equivalents of Phakopsora pachyrhizi DNA to establish standard curves, and the corresponding cycle threshold $\left(\mathrm{C}_{\mathrm{t}}\right)$ values (without $\mathrm{BSA}$ ) are given. B, Reactions contained 500,50,5.0, or $0.5 \mathrm{pg}$ of $P$. meibomiae DNA to establish standard curves, and the corresponding $C_{t}$ values (without $\mathrm{BSA}$ ) are given. $\mathbf{C}$ and $\mathbf{D}$, Primary assay is for $P$. pachyrhizi. $\mathbf{E}$ and $\mathbf{F}$, Primary assay is for $P$. meibomiae. $\mathbf{C}$ and $\mathbf{F}$, Quantity of target $\mathbf{D N A}$ found in the reaction, as calculated using the standard curve in A or B, is given. Abscissa, number of PCR cycles; ordinate, fluorescence (derivative, relative to ROX reference [not shown]). 
diluted only 1:20, PCR was completely inhibited in all reactions for those samples where CLS-Y was used (Table 3); in contrast, samples using CLS-VF gave a recovery of $32 \%$ for pJSH-B14, and host and fungal DNA were readily detected. Further dilution, with BSA added to the reaction, relieved inhibition, and quantification of the pJSH-B14 tracer for CLS-Y and CLS-VF extracts showed recovery averaging 51 and $42 \%$, respectively (after correction for volumetric losses). Quantification of host DNA using the $G m \mathrm{GAPDH}$ assay revealed an average yield increase of $22 \%$ for CLS-Y over CLS-VF extracts, paralleling the recovery increase for pJSH-B14. In contrast, quantification of fungal DNA using the $P$. pachyrhizi-specific assay revealed a 95\% yield increase over CLSVF when CLS-Y was used. These data indicate that, whereas CLSVF results in a preparation that requires less dilution to avoid false negatives by inhibitors, it also results in a much lower yield of fungal DNA. Whether this is owing to preferential extraction of DNA from mycelium, spores, or both from the infected tissue was not determined.

\section{Discussion}

The results demonstrate that none of the IC reactions or reaction components interfered with the performance of the primary assays (PpaIC in $P$. pachyrhizi, PpmIC in P. meibomiae, and HHIC in $F$. virguliforme) as measured by slope, y-intercept, and coefficient of correlation of test versus control assays. We did observe that, when the HHIC assay is run as a primary assay (e.g., in recovery experiments), the Core-Cy5 probe has potential to reduce the sensitivity of that assay and, therefore, should not be multiplexed when HHIC is being quantified. Both PpaIC and PmeIC constructs were shown to be effective at providing a positive signal in otherwise negative Q-PCR reactions and could thereby discriminate between falseand true-negative calls, as did the HHIC in $F$. virguliforme and other pathogen assays. It is noteworthy that, because only approximately 30 molecules of IC target were included in multiplexed reactions for qualitative purposes, they did not yield a positive signal until well after 32 amplification cycles (greater than $4 \times 10^{9}$ fold increase). This offered two important benefits. First, it potentially improved sensitivity to inhibitory compounds because, if reaction efficiency declined or polymerase decayed significantly, there would have been insufficient amplification for IC detection; thus, a false negative could be called. Second, the IC reaction would offer minimal competition with the primary assay for potentially limiting dNTPs. In reactions where the primary target was present in larger amounts, quantification could be accurately achieved and the IC did not amplify because reagents had been consumed by amplification of the primary targets. Nevertheless, any of these three IC assays could be performed independently with a higher quantity of target template, for the purpose of measuring the extent of PCR inhibition using the $\Delta \mathrm{C}_{\mathrm{t}}$ method (5) as a replacement for the Meloidogyne javanica $\beta$-actin assay and target.

In routine diagnostics, validated sample-processing methods and validated assay protocols are required for reliable and reproducible testing. Thus, "Standard Operating Procedures" are usually established and Quality Management practices such as ISO-9001, ISO17025, ISO-20838, and ISO-21569 (http://www.iso.org) may be adopted. Unfortunately in some situations, despite exhaustive preparation, "real-world" deployment may offer unforeseen and unpredictable challenges. In the results shown in Figure 5, for example, soybean leaf specimens were identically handled and extracted, yet the SR-4 specimen yielded a preparation that contained an inhibitor of Q-PCR that was not relievable by BSA alone, whereas the SR-1 preparation was readily amplified when BSA was added to the reaction. This may be reflective of a difference in host genotype, health, leaf age, environmental response, or preservation of the tissue at the time of collection, 23 to 26 years ago, and none of these factors were controllable at the time of our analysis. When testing specific inhibitors as additives to Q-PCR reactions, some inhibitors (EDTA and SDS) were more amenable to relief by dilution than by BSA addition, whereas another inhibitor (humic acid) was more amenable to relief by BSA supplement than by dilution. Furthermore, inhibitors such as xylan could be relieved by either method. Some inhibitors such as pectin may have only partial activity and merely reduce the sensitivity of the reaction without blocking it. Although an investigation of the biochemical mechanisms of inhibition is beyond the scope of this report, these cumulative results demonstrate the importance of robust DNA purification methods, of not relying upon a single inhibitor-avoidance technique, and of the value in using an IC to identify false-negative calls.

Having observed the degree of inhibition present after DNA purification from rust-infected leaves, we examined the potential for using a more robust DNA purification method. The FastDNA Spin kit commonly used to extract DNA from environmental and tissue specimens included several buffer options, with the following recommendations by the manufacturer: CLS-Y for yeast, algae, and fungi; CLS-VF for plant tissue; and CLS-TC for animal tissue, bone, and bacteria. In extracting fungal DNA from infected plant tissue, it was unclear which option would yield the best results, and anecdotal reports suggested that CLS-Y used for fungal extraction from leaf material would yield a green-brown tinted eluate and exhibit increased PCR-inhibition, absent if CLS-VF was chosen. We tested this by comparative extractions of uniformly powdered dry leaf tissue from rust-infected plants, each spiked with pJSHB14, and assayed for host DNA, pathogen DNA, and recovered pJSH-B14. The results shown in Table 3 demonstrate that, although there was less inhibition in extractives using CLS-VF, the overall yield of fungal DNA was much higher when CLS-Y was used. In the assays for both $G m$ GAPDH and HHIC utilizing high dilution and BSA, the CLS-Y buffer yielded approximately $22 \%$ more DNA compared with CLS-VF, and this may reflect an improved binding of DNA to the glassmilk matrix in CLS-Y. Thus, the extraction improvement for fungal DNA offered by CLS-Y over CLS-VF is approximately $60 \%[96,800 /(49,600 \times 1.22)=1.60]$. However, further dilution and the addition of BSA to the Q-PCR reaction did not substantially increase the observed quantity of $P$. pachyrhizi DNA when CLS-VF was employed, suggesting that it may represent a cleaner or more robust extraction chemistry.

Other researchers, faced with the problem of false negatives, have taken steps such as those outlined in the introduction. We did develop our own assay for a host housekeeping gene but do not use it here as an internal control because host DNA is not present when

Table 3. Recovery of DNA from $50 \mathrm{mg}$ of powdered leaf tissue using two extraction buffers (five replicates each)

\begin{tabular}{|c|c|c|c|}
\hline \multirow[b]{2}{*}{ Buffer (dilution) $^{\mathbf{b}}$} & \multicolumn{3}{|c|}{ Sample ${ }^{a}$} \\
\hline & pJSH-B14 (copies/mg of tissue) ${ }^{\mathrm{c}}$ & GmGAPDH (ng/mg tissue) & Phakopsora pachyrhizi (SEq/mg of tissue) ${ }^{\mathrm{d}}$ \\
\hline CLS-Y (1:20) & 0 & 0 & 0 \\
\hline CLS-VF $(1: 20)$ & $1,650(\mathrm{sd}=7.2 \%)[32 \%$ recovery $]$ & $302(\mathrm{sd}=1.3 \%)$ & $45,900(\mathrm{sd}=5.4 \%)$ \\
\hline CLS-Y $(1: 100)$ & $2,660(\mathrm{sd}=23 \%)[51 \%$ recovery $]$ & $490(\mathrm{sd}=3.9 \%)$ & $96,800(\mathrm{sd}=5.6 \%)$ \\
\hline CLS-VF (1:100) & $2,170(\mathrm{sd}=20 \%)[42 \%$ recovery $]$ & $401(\mathrm{sd}=1.1 \%)$ & $49,600(\mathrm{sd}=4.4 \%)$ \\
\hline
\end{tabular}


urediniospores are to be quantified from environmental samples. Instead, we elected to use an exogenous target. Although the IC described by Honeycutt et al. (10) was at first appealing as a model, it was not designed for Q-PCR (i.e., it had no probe-binding sequence), and it was somewhat longer than we prefer for this purpose; the necessity of reoptimizing the primers and finding a suitable probe eliminated any empirical savings by its use. Similarly, the IC described by Cone et al. (1) predated Q-PCR technology and used natural Drosophila DNA sequences. In a few instances, Q-PCR ICs were derived from natural sequences $(2,8)$; however, in addition to the potential pitfalls related to using natural DNAs, the nucleotide sequence of the IC target molecule (in these examples, carried by a plasmid) was not revealed in the publication, and no reference to an archival repository was given. Further, one of those ICs was derived from a select agent (Bacillus anthracis), which may restrict its availability to a narrow field of investigators. Rosenstraus et al. (21) developed a series of IC molecules that contained a unique probe-binding region, flanked by primer-binding sequences identical to the primer sequences of a series of primary assays, and cloned the intact oligonucleotides into pUC18, for use in Q-PCR. Unfortunately, they did not reveal the proprietary nucleotide sequence data, thus denying free use of their intellectual property to the wider sciences. Finally, there is at least one exogenous internal control kit commercially available (Applied Biosystems), however, it utilizes not only proprietary target and primer sequences but also a limited spectral range of fluorescent probes. As a result, many workers find themselves without readily available ICs, and either omit them entirely or "make do" with parallel assays to assess potential inhibition. For example, the $M$. javanica $\beta$-actin gene assay and cloned $\beta$-actin gene fragment were used to evaluate inhibition in samples to be tested for the soybean fungal pathogen Phialophora gregata in separate reactions (17), but that clone is not widely available and there is potential for interference by sequence homologues that might be adventitiously present.

To facilitate better diagnostic and discovery research at a nominal cost, we have developed IC assays and corresponding targets of artificial sequence that may have wide utility. Clearly, PpaIC and PmeIC will be useful mainly in soybean rust testing, but their shared core oligonucleotide sequence may be augmented by the primers corresponding to various other Q-PCR assay targets to readily produce a matching IC at a trivial expense, utilizing the same core probe. One nanomole of IC oligo is sufficient for over $10^{12}$ reactions. We have already adapted the core sequence to produce ICs ranging in length from 80 to $96 \mathrm{nt}$ for use with several other pathogen genera in our laboratory (data not shown). In contrast, HHIC carries its own unique primer-binding regions and, thus, has potential for immediate use in a broad range of multiplexed Q-PCR assays when a natural IC against false negatives is unavailable. Furthermore, because the HHIC sequence is part of a 3,600-bp plasmid, when employed as an exogenous DNA tracer during assay and extraction method development and process improvement studies, it can be expected to behave as endogenous double-stranded DNA. We have also employed this plasmid as a calibrator molecule in relative Q-PCR (data not shown), with analysis by the $\Delta \Delta C_{t}$ method $(6,15)$. One microgram of linearized pJSH-B14 is sufficient IC for over $10^{9}$ reactions.

PpaIC and PmeIC utilize the primer sequence of the primary assay; therefore, the control amplification will always be thermally compatible with the primary reaction. However, if a primary assay is inefficient or generates an amplicon significantly longer than those of our ICs, it may suffer some change in detection limit, and modifications to the IC sequence might be required for successful multiplexing. We designed the IC probes to have melting points matching those of our primary assay probes (Table 1). Assay design considerations generally link the $\mathrm{T}_{\mathrm{m}}$ of the probe to that of the primers and, as such, other assay probes may deviate thermally in this regard, necessitating modification of the CoreIC sequence to achieve probe binding and release of the fluorescent reporter. This is similar to the challenge presented by designing higher degrees of multiplex (several primary targets at once), wherein all assays need to be compatible. Although we used Cy5 (for PpaIC and PmeIC) and HEX (for HHIC) as fluors in this work, the same core probe sequence can be synthesized with any available reporter dye, to suit the needs of the investigators and equipment. Any of the ICs might also be used in diagnostic endpoint TaqMan PCR although, for that purpose, a greater quantity of IC template would need to be spiked in, perhaps 3,000 copies per reaction, to yield a substantial endpoint signal. With the sequence information we provide here, an appropriate IC assay to validate true-negative results and detect false-negative calls may be devised for a broad spectrum of Q-PCR applications in minutes, and at relatively low cost.

\section{Acknowledgments}

We thank C. R. Bowen for assistance with statistical analyses and interpretation, J. Hennen and T. A. Pham for archival rust-infected specimens, and the United Soybean Board for financial support.

\section{Literature Cited}

1. Cone, R. W., Hobson, A. C., and Huang, M. L. W. 1992. Coamplified positive control detects inhibition of polymerase chain reactions. J. Clin. Microbiol. 30:3185-3189.

2. Courtney, B. C., Smith, M. M., and Henchal, E. A. 1999. Development of internal controls for probe-based nucleic acid diagnostic assays. Anal. Biochem. 270:249-256.

3. Dellaporta, S. L., Wood, J., and Hicks, J. B. 1983. A plant DNA minipreparation: version II. Plant Mol. Biol. Rep. 1:19-21.

4. Ding, J., Jia, J. Yang, L., Wen, H., Zhang, C., Liu, W., and Zhang, D. 2004 Validation of a rice specific gene, sucrose phosphate synthase, used as the endogenous reference gene for qualitative and real-time quantitative PCR detection of transgenes. J. Agric. Food Chem. 52:3372-3337.

5. Frederick, R. D., Snyder, C. L., Peterson, G. L., and Bonde, M. R. 2002 Polymerase chain reaction assays for the detection and discrimination of the soybean rust pathogens Phakopsora pachyrhizi and P. meibomiae. Phytopathology 92:217-227.

6. Gao, X., Jackson, T. A., Lambert, K. N., Li, S., Hartman, G. L., and Niblack, T. L. 2004. Detection and quantification of Fusarium solani f. sp. glycines in soybean roots with real-time quantitative polymerase chain reaction. Plant Dis. 88:1372-1380.

7. Griffiths, K., Emslie, K., and Vesey, G. 2004. Absolute copy numbers for DNA controls. In: Bti, www.biotech-online.com.

8. Hartman, L. J., Coyne, S. R., and Norwood, D. A. 2005. Development of a novel internal positive control for TaqMan based assays. Mol. Cell. Probes 19:51-59.

9. Haudenshield, J. S., and Hartman, G. L., 2008. Synthetic internal control sequences to increase negative call veracity in multiplexed, quantitative PCR assays for Phakopsora pachyrhizi. (Abstr.) Phytopathology 98:S66.

10. Honeycutt, R., Sobral, B. W., and McClelland, M. 1997. Polymerase chain reaction $(\mathrm{PCR})$ detection and quantification using a short PCR product and a synthetic internal positive control. Anal. Biochem. 248:303-306.

11. Jeong, S. C., Pack, I. S., Cho, E. Y., Youk, E. S., Park, S., Yoon, W. K., Kim, C. G., Choi, Y. D., Kim, J. K., and Kim, H. M. 2007. Molecular analysis and quantitative detection of a transgenic rice line expressing a bifunctional fusion TPSP. Food Control 18:1434-1442.

12. Jiang, J., Alderisio, K. A., Singh, A., and Xiao, L. 2005. Development of procedures for direct extraction of Cryptosporidium DNA from water concentrates and for relief of PCR inhibitors. Appl. Environ. Microbiol 71:1135-1141.

13. Kellog, D. E., Sninsky, J. J., and Kwok, S. 1990. Quantitation of HIV-1 proviral DNA relative to cellular DNA by the polymerase chain reaction. Anal. Biochem. 189:202-208.

14. Kontanis, E. J., and Reed, F. A. 2006. Evaluation of real-time PCR amplification efficiencies to detect PCR inhibitors. J. Forensic Sci. 51:795-804.

15. Livak, K. J., and Schmittgen, T. D. 2001. Analysis of relative gene expression data using real-time quantitative PCR and the $2^{-\Delta \Delta C t}$ method. Methods 25:402-408.

16. Malvick, D. K., and Grunden, E. 2005. Isolation of fungal DNA from plant tissues and removal of DNA amplification inhibitors. Mol. Ecol. Notes 5:958-960.

17. Malvick, D. K., and Impullitti, A. E. 2007. Detection and quantification of Phialophora gregata in soybean and soil samples with a quantitative, realtime PCR assay. Plant Dis. 91:736-742.

18. McDevitt, J. J., Lees, P. S. J., Merz, W. G., and Schwab, K. J. 2007. Inhibition of quantitative PCR analysis of fungal conidia associated with indoor air particulate matter. Aerobiologia 23:35-45.

19. Nolan, T., Hands, R. E., Ogunkolade, W., and Bustin, S. A. 2006. SPUD: quantitative PCR assay for the detection of inhibitors in nucleic acid preparations. Anal. Biochem. 351:308-310.

20. Noonan, K. E., Beck, C., Holzmayer, T. A., Chin, J. E., Wunder, J. S., Andrulis, I. L., Gazdar, A. F., Willman, C. L., Griffith, B., Von Hoff, D. D. and Roninson, I. B. 1990. Quantitative analysis of MDR1 (multidrug resis- 
tance) gene expression in human tumors by polymerase chain reaction. Proc. Natl. Acad. Sci. USA 87:7160-7164.

21. Rosenstraus, M., Wang, Z., Chang, S. Y., DeBonville, D., and Spadoro, J. P. 1998. An internal control for routine diagnostic PCR: design, properties, and effect on clinical performance. J. Clin. Microbiol. 36:191-197.

22. Sambrook, J., and Russell, D. W. 2001. Pages 1.32-1.34 in: Molecular Cloning: A Laboratory Manual, 3rd ed. Cold Springs Harbor Laboratory
Press, Cold Spring Harbor, NY.

23. Stenman, J., and Orpana, A. 2001. Accuracy in amplification. Nat. Biotechnol. 19:1011-1012.

24. Ursi, J. P., Ursi, D., Ieven, M., and Pattyn, S. R. 1992. Utility of an internal control for the polymerase chain reaction. Application to detection of $M y$ coplasma pneumoniae in clinical specimens. Acta Pathol. Microbiol. Immunol. Scand. 100:635-639. 